\title{
Alejandro Salgado Martínez: Los sonetos de José María Blanco White. Prólogo de Esteban Torre. Sevilla: Diputación de Sevilla, Servicio de Archivo y Publicaciones, 2013.
}

La figura de José María Blanco White (Sevilla, 1775 - Liverpool, 1841) es la imagen del luchador que no encuentra descanso y lleva consigo las cicatrices de sus muchos combates. La patria, la religión, la filosofía, la lengua y hasta la literatura fueron campos de batalla donde se vio obligado a batirse en defensa de sus ideales y, casi siempre, a contracorriente de lo aceptado por la mayoría de cuantos le rodearon. Tan agitada vida ha sido objeto de estudio desde los más diversos puntos de vista, aunque su valor estrictamente literario se ha visto en ocasiones oscurecido, e incluso deformado, en aras de la prevalencia de otros aspectos que, como polemista relevante de su tiempo, pasaron a ocupar en distintos momentos el primer plano de atención. Más aún, si como literato su prosa fue reivindicada prontamente, fue necesario esperar largo tiempo para que su poesía recibiera el mismo trato de la crítica especializada. En esta dirección, aparte de los trabajos muy estimables de Vicente Llorens, ${ }^{1}$ hay que mencionar en lugar preferente los que partieron de la Universidad de Sevilla y de tres de sus más destacados investigadores, los profesores Garnica Silva y Díaz García, ${ }^{2}$ catedráticos de Lengua Inglesa, y el

${ }^{1}$ Cfr. LloRens, Vicente: Liberales y románticos. Una emigración española en Inglaterra (1823-1834), México: Fondo de Cultura Económica, 1954; José María Blanco White. Antología de obras en español, Barcelona: Labor, 1971; «Historia de un famoso soneto», en R. Pincus Sigele y G. Sobejano (eds.), Homenaje a Casalduero. Crítica y poesía, Madrid: Gredos, 1972, pp. 299-313.

${ }^{2}$ Cfr. Garnica Silva, Antonio y Díaz García, Jesús: Obra poética competa, Madrid: Visor, 1994; «El soneto 'Night and Death' de José Blanco White», en Joaquín Álvarez Barrientos y José Checa Beltrán (eds.): El siglo que llaman ilustrado. Homenaje a Francisco Aguilar Piñal, Madrid: CSIC, 1996, pp. 429-450. Por separado, ambos investigadores cuentan también con destacadas publicaciones sobre el tema. Entre ellas, destacaremos las siguientes: GARnicA SiLva, Antonio: «Blanco White, poeta inglés», Filología moderna, 1975-1976, 56-58, pp. 79-90; «Los sonetos de Blanco White (A propósito del soneto "bíblico": "El despertar 
profesor Torre Serrano, ${ }^{3}$ catedrático de Teoría de la Literatura y Literatura Comparada, quien además encabeza como prologuista el libro que reseñamos.

En esa línea de trabajo, que pretende subrayar especialmente los logros poéticos de Blanco, se sitúa el trabajo del joven profesor Alejandro Salgado Martínez, titulado Los sonetos de José María Blanco White. Esta obra, que ahora ha visto la luz editada con total pulcritud por el Servicio de Archivo y Publicaciones de la Diputación de Sevilla, le ha merecido a su autor el premio Archivo Hispalense del año 2011, en la modalidad de Literatura, por la excelencia de su tarea investigadora, fruto final de la reelaboración de la que fue su tesis doctoral, leída en 2010 en la Facultad de Filología de la Universidad de Sevilla, y con la que obtuvo asimismo la máxima calificación del tribunal.

Esta obra presenta una estructura sólida y claramente definida, acorde por completo con lo que el título del trabajo pretende elucidar. De este modo, podríamos señalar en él tres grandes bloques. En primer lugar, se esboza la situación contextual que afecta al proceso creativo y que dio lugar a la producción de estos sonetos objeto del trabajo. Aquí, el autor analiza la vida de Blanco de una manera concisa, haciendo referencia exclusivamente a aquellos aspectos de su biografía que influyen de manera decisiva en la construcción de su poesía y, por tanto, se omite cualquier casuística entorpecedora que no obedezca a sus pretensiones filológicas y poéticas. A continuación, nos ofrece un estudio de conjunto de la obra exclusivamente en verso de Blanco White, donde se indican sus correspondientes etapas y las características que ilustran cada una de éstas. Y, por último, en un breve y preciso capítulo, se desgranan las ideas del poeta sevillano sobre el soneto como estrofa particular, aduciendo los testimonios pertinentes para que se comprenda y valore adecuadamente dentro de su producción lírica.

Tras esta primera parte, Alejandro Salgado aborda lo que será el núcleo medular de su libro. Así, mientras el segundo bloque lo dedica específicamente al estudio de los sonetos ingleses -observando con todo detalle sus variantes, traducciones y fuentes-, el tercero, y último, será destinado a enjuiciar con método equivalente los sonetos que

de Adán”)», Miscelánea Comillas, 1983, XLI, 78-79, pp. 433-438. DíAz GARCÍA, Jesús: «Poemas en inglés: Recollection of a Night at Sea, de Blanco White», Celacanto, 1984-1985, 1-2, pp. 77-85.

${ }^{3}$ Cfr. Torre Serrano, Esteban: «La noche y la muerte, de José M. Blanco White», Anglo-American Studies, 1988, VIII, 2, pp. 222-225; «Poesía y traducción poética: los sonetos ingleses de José María Blanco White», Archivo Hispalense, 2007, XC, 273-275, pp. 281-294. 
Blanco escribió en castellano al final de sus días. La importancia de la tarea llevada a cabo en el estudio de los sonetos ingleses es puesta de relieve desde el mismo prólogo por el profesor Esteban Torre -experto metricista, poeta y traductor $-{ }^{4}$ por lo minucioso del análisis efectuado de todas y cada una de las traducciones surgidas del traslado de dichos sonetos, ya se hayan vertido en verso o en prosa a la lengua española, y por el exquisito rigor filológico y comparatista con el que son analizadas. En ambos bloques se proporciona al lector un documentado conjunto de datos esclarecedores y precisos en lo que respecta a las fuentes, versiones, interpretaciones y significados de todos los sonetos escritos por el poeta oriundo de la ciudad del Guadalquivir.

Asimismo, es digno de destacar, dentro de esa labor de documentación directa que ha realizado el autor de este trabajo de investigación el estudio de los manuscritos del propio Blanco White y que se encuentran diseminados por la Sydney Jones Library de la Universidad de Liverpool, el Harris Manchester College Library en Oxford, la Firestone Library de la Universidad americana de Princeton, en la Biblioteca Menéndez Pelayo de Santander y en el Instituto Feijoo de Estudios del siglo XVIII de Oviedo. Esta observación directa da las fuentes le ha permitido sustentar sobradamente sus afirmaciones sobre dataciones de los poemas y la consideración de sus variantes con el rigor exigido en una labor de estas características. En este sentido, es un acierto de la presente edición el breve pero suficiente número de láminas que se nos muestran a lo largo del libro para cotejo del lector interesado.

Pero lo más importante, claro está, no es sólo que la estructuración sea por completo apropiada al propósito de la obra, sino que, a lo largo de sus casi tres centenares de páginas, da cumplida elaboración a cuanto se ha señalado anteriormente con absoluta competencia. La propia extensión del trabajo, dado lo reducido del corpus objeto de análisis, esos siete sonetos -tres en lengua inglesa y cuatro en español- escritos en total por el poeta sevillano es también indicio de la minuciosidad con la que ha ejecutado su tarea Alejandro Salgado a lo largo de los distintos capítulos.

Otro aspecto interesante y digno de consideración por parte del autor es que estos sonetos fueron compuestos en dos periodos de tiempo claramente delimitados y ambos de muy escasa duración. Así,

\footnotetext{
${ }^{4}$ Las traducciones que el profesor Esteban Torre ha realizado de los sonetos de Blanco figuran comentadas en el propio libro en las siguientes páginas: 137-138, 207-208 y 223-224. Es de destacar que con la del primero de estos tres poemas, «La noche y la muerte», el poeta y catedrático de la Hispalense obtuvo el Primer Premio en el II Certamen Nacional de Traducción Poética, celebrado en Cáceres en mayo de 1988.
} 
en el caso de los escritos en lengua inglesa, su composición se encuadra en el plazo de los cinco meses que transcurren desde diciembre de 1825 a abril de 1826 y llevan por título: «Night and Death»-el más conocido y versionado de todos-, «On hearing myself for the first time called an old man»y, por último, «On my love of sublime poetry». Sólo estos sonetos, y sobre todo el primero de ellos, resultan suficientes para otorgar a José María Blanco White el derecho a pertenecer al canon de la literatura inglesa. Como señala Salgado, es de hecho el único escritor nacido en España que figura, y con una destacable extensión, en el prestigioso diccionario biográfico inglés Dictionary of National Biography, hecho especialmente notable si se tiene en cuenta, además de su origen, lo reducido de su producción.

Por su parte, los sonetos escritos en castellano se sitúan en un arco temporal equivalente al anterior, entre el 30 de septiembre de 1839 y el 3 de febrero de 1840, ya muy próximo el final de su vida. Dos de ellos están dedicados a su amigo, el también poeta sevillano Alberto Lista: "A Lista», «Poder del recuerdo de mi amigo Lista»; otro a su sobrina, «A D. . Ana María Beck», y cierra la breve serie el titulado «La revelación interna». Con ello, Blanco vendría a cerrar un círculo creativo y poético que va desde sus inicios en la Academia de Letras Humanas de Sevilla, su consagración como escritor en lengua inglesa -en prosa y verso-, y su regreso postrero a esa patria imposible de olvidar que es la lengua. A punto de concluir su camino vital, Blanco se exige a sí mismo probarse en el mayor de los esfuerzos poéticos: ensayar de nuevo la forma estrófica del soneto, aquélla que él mismo calificó de gema perfecta que siempre puede llevarse en la memoria, como una preciosa joya que permite ser admirada cuando se quiera y extasiarse con deleite en su contemplación.

Sin duda, el núcleo de cuanto venimos exponiendo puede sintetizarse en el estudio que en las páginas de este libro se hace del más conocido, alabado y traducido de todos estos sonetos: «Night and Death», y que no en vano ocupa el lugar central del trabajo. Alejandro Salgado le aplica un modelo de análisis que repetirá sucesivamente en el resto de poemas estudiados. Así, se analizan sus variantes, que son comentadas en profundidad. Se presentan las distintas traducciones del soneto que en lengua española se han ofrecido a una orilla y otra del Atlántico, dando lugar así a un oportuno y fundamentado debate de Teoría literaria sobre el proceso de traducción y, especialmente, sobre la tan traída y llevada cuestión de la posibilidad o no de verter la poesía de una lengua a otra sin alterar las características formales básicas del poema primigenio, incluyendo los fenómenos de ritmo y 
rima. Se enjuician además esas diferentes versiones que se presentan y se hace un oportuno ejercicio de crítica literaria; de modo que el autor de este libro no duda en manifestar sus opiniones con juicio claro y pertinente, señalando los distintos logros, vicios o libertades que encuentra en dichas traducciones con una exhaustividad digna de encomio. Asimismo, el trabajo proporciona un notable conjunto de notas a pie de página donde, sin distraer el curso principal de la lectura, se apostilla y documenta fehacientemente todo lo incluido en el cuerpo de texto, haciendo demostración de su conocimiento en los distintos campos de estudio en los que se adentra el trabajo y como testimonio de su destacada solvencia, tanto en los aspectos teóricos como en el dominio de la traducción de la lengua inglesa.

Del mismo modo, se analizan las fuentes de las que se nutren estos sonetos de Blanco, sin que esta tarea sea una mera cuestión de acopio de materiales diversos o meramente aproximativos; sino que el profesor Salgado aprovecha para señalar los parecidos y diferencias que observa con respecto a cada una de aquellas fuentes originales y el resultado final que logra el poeta sevillano, efectuando así, a la hora de enjuiciar las diversas traducciones a la que estos sonetos dan lugar, un fino ejercicio de comparatismo.

Es de destacar igualmente, dentro de la consideración del análisis formal de los textos estudiados, el estudio que presenta sobre las modificaciones que Blanco White plantea sobre el llamado soneto isabelino, y cómo ya en el primero, y más importante de todos, fijó el modelo que habría de utilizar en el resto de sus sonetos ingleses. Así, si los tres serventesios iniciales del modelo fijado en el soneto isabelino se rematan en un pareado final, Blanco cambia la primera parte de la estructura estrófica, por contaminación con la del soneto petrarquista, que había practicado en su juventud, y prefiere iniciarlo con dos cuartetos de rima idéntica seguidos de un serventesio al que se añade, como remate estrófico, el pareado final característico de la fórmula shakesperiana. Es una manera más de testimoniar la fusión entre su formación literaria inicial, de carácter clasicista acorde con la academia hispalense, y la plenitud que alcanzaría su literatura en esa singladura que lo llevó de Sevilla a Ufton, donde compuso estos poemas de singular valía.

El análisis hermenéutico ocupa también un lugar adecuado dentro de esta investigación. El profesor Salgado es consciente de la necesidad de señalar las claves interpretativas de este conjunto de sonetos para que nada quede fuera del alcance del lector de estas páginas. El poder del contexto histórico-literario, las lecturas efectuadas por 
Blanco, los estudiosos de su obra, los mismos traductores, el propio y fundamentado conocimiento del autor toman la relevancia oportuna para poner de manifiesto la valía y el exacto significado de las palabras, los símbolos y la visión que Blanco White quiere transmitirnos con sus poemas. Nada queda al margen de cuanto precisa este análisis, desde la idea de lo sublime a los planteamientos de Wordsworth, desde la visión de Bacon o de Milton a la de autores contemporáneos.

La consideración de los sonetos escritos en español durante su dilatada estadía inglesa, aunque sólo los escribiera cercana ya su muerte, ocupa la parte final del libro. El profesor Salgado se detiene, en primer lugar, en el repaso de las circunstancias vitales que impulsan a Blanco a volver a su lengua materna después de tantos años de escritura en otra distinta a aquélla, y aun cuando reconoce una cierta incapacidad para el manejo del español después de haberle sido ajeno por largo tiempo a cualquier producción de carácter literario. Interesa especialmente esta cuestión cuando la forma escogida para ello es la de una de las estrofas más restrictivas y exquisitas de la panoplia poética. Para su explicación, Alejandro Salgado aduce los testimonios de primera mano que el propio Blanco manifiesta en las cartas que de él se conservan. Hace también el autor aquí un cotejo de los manuscritos conservados de todos los sonetos y examina sus variantes, proporcionando al lector tanto el contexto de cada uno como la interpretación de éstos e, igualmente, nos ofrece su opinión valorativa al lado de cuantos críticos se han acercado a esta parte de su producción literaria.

En resumen, la obra de Alejandro Salgado Martínez Los sonetos de José María Blanco White cumple con creces los objetivos que pueden esperarse de una investigación literaria de solvencia y sus páginas se hacen justamente acreedoras el premio otorgado por la Diputación de Sevilla, que vuelve a hacer gala con esta publicación de su exquisito cuidado en la edición de los textos que ofrece en su amplio catálogo y del fomento de estudios de envergadura en los distintos campos del saber. Sin duda, la reivindicación que hace su autor de la figura de Blanco White dentro de la poesía de su tiempo, al margen de cuestiones ideológicas y extraliterarias, y como uno de los casos excepcionales que merece figurar en el canon de dos lenguas distintas, queda plenamente atestiguada a lo largo de los capítulos de este libro.

Manuel Romero Luque Universidad de Sevilla 